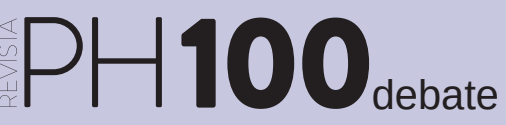

a debate Repositorios y redes sociales académicas para la transferencia del conocimiento abierto

| coordina Remedios Melero Melero

\title{
La producción científica en abierto y los repositorios institucionales como instrumentos de difusión y protección antiplagio. El caso de Riunet de la UPV
}

Francisca Ramón Fernández | Dpto. de Urbanismo, Universitat Politècnica de València

URL de la contribución <www.iaph.es/revistaph/index.php/revistaph/article/view/4621>

Cuando nos planteamos la producción científica surge la cuestión de si el acceso abierto, el open access, va a suponer una merma en nuestro perfil; si nuestra actividad se va a ver sometida a un plagio; y si vamos a quedar desprotegidos ante la posibilidad de que el acceso sea diferente a un acceso cerrado o limitado.

Nada más lejos de la realidad. Actualmente, el acceso al conocimiento y su difusión a través de repositorios aporta numerosas ventajas respecto a la producción científica de un autor puesto que, de otra forma, sin ese acceso abierto, la transferencia de conocimiento no sería completa para todos los sectores y perfiles.

En realidad, si el conocimiento no se difunde, es como si no existiera. Ciertamente, si no logramos que la investigación llegue a ser conocida, no podrá servir para generar una investigación de futuro.

Encontramos el respaldo legal en el artículo 37.1-3 y 6 de la Ley 14/2011, de 1 de junio, de la Ciencia, la Tecnología y la Innovación, que establece el impulso para el desarrollo de repositorios, propios o compartidos, de acceso abierto a las publicaciones de su personal de investigación. En el caso de que la investigación se haya financiado con fondos públicos se publicará una versión digital de la versión final de los contenidos aceptados para su publicación en publicaciones de investigación. La versión electrónica se publicará en repositorios de acceso abierto reconocidos en el campo de investigación o en repositorios institucionales de acceso abierto. Todo ello sin perjuicio de los acuerdos para la atribución o transferencia a terceros de los derechos sobre las publicaciones y sin que se aplique cuando los derechos de los resultados de la actividad de I+D+i sea susceptibles de protección.
A ello también se une el tan discutido tema de las citas en la investigación. Si un artículo es accesible en abierto tiene más opciones de ser citado que uno que no lo está. No hay que olvidar que internet, los repositorios y las bases de datos se han convertido en un instrumento de consulta por parte del investigador, de forma habitual, y antes va a tener acceso a un documento en abierto que a uno que no lo está.

Junto a ello, hay otro aspecto muy interesante que se ha de considerar; el de la propiedad intelectual de la obra original, regulado por el Real Decreto Legislativo 1/1996, de 12 de abril, por el que se aprueba el texto refundido de la Ley de Propiedad Intelectual, regularizando, aclarando y armonizando las disposiciones legales vigentes sobre la materia. Es decir, el acceso abierto se convierte en una herramienta antiplagio muy importante, ya que a través de los distintos programas de los que se dispone (por ejemplo, Turnitin), es más fácil detectar si ha habido plagio de una obra que está accesible en abierto, de una que no lo está, y que puede haberse reproducido sin cita, precisamente porque no lo va a detectar un programa informático.

Otro aspecto relevante es la utilización de material protegido por derechos de autor y que se encuentra disponible en los repositorios de acceso abierto para ser utilizado en el ámbito docente e investigador. Hay que tener en cuenta lo indicado en el art. 32 del Real Decreto Legislativo $1 / 1996$, en cuanto a las citas y reseñas e ilustración con fines educativos o de investigación científica, que permite la inclusión en una obra propia de fragmentos de obras ajenas. Deberá ser utilizado siempre con dichos fines en la medida justificada por ese fin, con indicación de la fuente y autoría (RAMÓN FERNÁNDEZ, 2013: 235). 
Aquí podríamos hablar, en el caso de la docencia, de los conocidos como MOOC y la inserción de elementos ajenos teniendo en cuenta las limitaciones que establece la norma mencionada (RAMÓN FERNÁNDEZ, 2014: 79; PRÓSPER RIBES; RAMÓN FERNÁNDEZ, 2019: 123).

En el caso de RiuNet, el repositorio institucional de la Universitat Politècnica de Valencia, tras la implantación del Plan de Docencia en Red en el que el profesorado realiza grabaciones para la docencia e investigación, se incluyen tanto documentos escritos, como trabajos académicos y material multimedia. Tal y como se indica en el apartado "Información sobre derechos de autor" del propio repositorio, se trata de un canal de difusión para que el autor, teniendo en cuenta sus derechos morales, pueda ceder o no los derechos de explotación o económicos.

Se depositan tanto obras inéditas como ya publicadas, de acuerdo con las condiciones recogidas en los siguientes documentos:

$>$ El Acuerdo marco de cesión de derechos de autor.

$>$ El Contrato para el depósito de tesis doctorales, para las que se hayan leído antes de la entrada en vigor del Real Decreto 99/2011, de 28 de enero, por el que se regulan las enseñanzas oficiales de doctorado.

\section{> Autorización para la difusión de trabajos académicos.}

La difusión de las obras puede realizarse mediante una licencia de reserva de todos los derechos o una licencia Creative Commons.

Con la finalidad y el compromiso del acceso abierto, la Universitat Politècnica, a través de su Editorial y la Biblioteca, ha depositado los artículos de revistas publicadas en la plataforma OJS de la Universidad, conocida como Poli[Papers], ha establecido una pasarela entre la producción científica publicada por la editorial y el repositorio y otra pasarela para los Congresos OCS y Riunet, abarcando la totalidad de las publicaciones (MARTíNEZ-

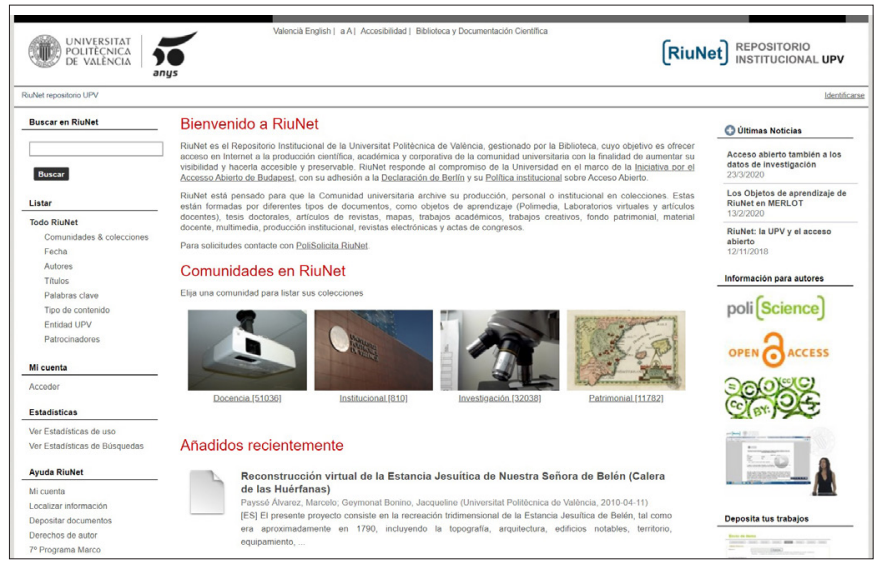

RiuNet, el repositorio institucional de la Universitat Politècnica de Valencia

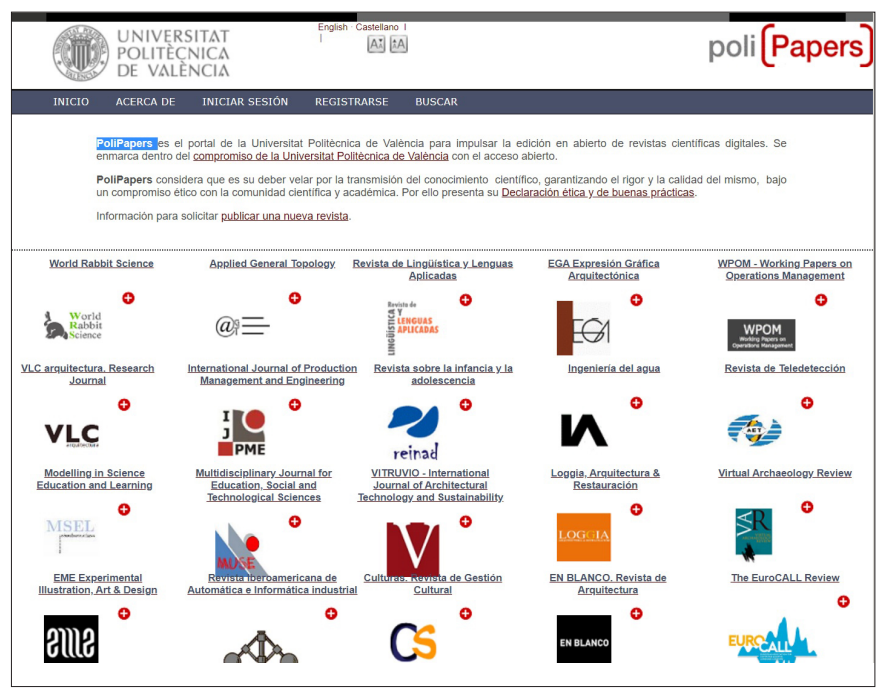

Poli[Papers]

GALINDO; PÉREZ GARCÍA; RIBELLES AGUILAR, 2018: 285).

Todo ello nos lleva a replantearnos el concepto de reutilización, que no debe estar reñido con la producción científica y el acceso abierto, ni con la propiedad intelectual. La autoría debe referirse siempre y, además, se debe reconsiderar que el investigador que publica en abierto abierto sea evaluado en idénticas condiciones del que no lo hace. Las publicaciones en acceso abierto tienen una calidad similar a la de una publicación no accesible; no por estar en abierto la calidad de la publicación 
_a debate Repositorios y redes sociales académicas para la transferencia del conocimiento abierto | coordina Remedios Melero Melero

es inferior, por lo que los parámetros para la evaluación deben ser similares tanto en el acceso abierto como en el que no lo es.

\section{BIBLIOGRAFÍA}

- LEY 14/2011, de 1 de junio, de la Ciencia, la Tecnología y la Innovación. Boletín Oficial del Estado, n. ${ }^{\circ} 131$, de 2 de junio de 2011 <https://www.boe.es/buscar/act. php?id=BOE-A-2011-9617> [Consulta: 30/03/2020]

- MARTÍNEZ-GALINDO, F.; PÉREZ GARCÍA, M. ${ }^{a}$ R.; RIBELLES AGUILAR, J. V. (2018) Editorial y RiuNet trabajando juntos para llegar más lejos. En Ecosistemas del Acceso Abierto [en línea]. Salamanca: Universidad de Salamanca, 2018, pp. 285-298 <https://gredos.usal.es/bitstream/ handle/10366/138629/978-84-9012-774-2-0285-0297. pdf? sequence $=1 \&$ isAllowed=y $>$ [Consulta: 30/03/2020]

- PRÓSPER RIBES, J.; RAMÓN FERNÁNDEZ, F. (2019) MOOC y derechos de autor en la enseñanza online en el Derecho español. La Propiedad Inmaterial [en línea], n. ${ }^{\circ} 27$, 2019, pp. 121-147 <https://revistas.uexternado.edu.co/index. php/propin/article/view/6075/7793> [Consulta: 29/03/2020]

- RAMÓN FERNÁNDEZ, F. (2013) La redefinición de las excepciones en materia de propiedad intelectual. Derecho de cita, plagio e internet. En Libertad de expresión e información en internet. Amenazas y protección de los derechos personales. Madrid: Centro de Estudios Políticos y Constitucionales, 2013, pp. 233-258

- RAMÓN FERNÁNDEZ, F. (2014) La realización de material audiovisual para los cursos masivos en abierto (MOOC): cuestiones legales no resueltas en el ámbito de la propiedad intelectual. IDP. Revista de Internet, Derecho y Política [en línea], n. ${ }^{\circ}$ 9, 2014, pp. 78-19 <https://idp.uoc.edu/articles/ abstract/10.7238/idp.v0i19.2222/> [Consulta: 28/03/2020]

- REAL DECRETO 99/2011, de 28 de enero, por el que se regulan las enseñanzas oficiales de doctorado. Boletín Oficial del Estado, n. ${ }^{\circ}$ 35, de 10 de febrero de $2011<$ https://www. boe.es/buscar/pdf/2011/BOE-A-2011-2541-consolidado.pdf> [Consulta: 30/03/2020]

- REAL DECRETO LEGISLATIVO 1/1996, de 12 de abril, por el que se aprueba el texto refundido de la Ley de Propiedad Intelectual, regularizando, aclarando y armonizando las disposiciones legales vigentes sobre la materia. Boletín Oficial del Estado, n. ${ }^{\circ} 97$, de 22 de abril de 1996 <https://www.boe.es/ buscar/act.php?id=BOE-A-1996-8930> [Consulta: 30/03/2020] 